\title{
Decoding the Role of Glycans in Malaria
}

\author{
Pollyanna S. Gomes ${ }^{1}$, Daniel F. Feijó ${ }^{2}$, Alexandre Morrot ${ }^{1,3 *}$ and Celio G. Freire-de-Lima ${ }^{4 *}$ \\ ${ }^{1}$ Departamento de Imunologia, Instituto de Microbiologia, Universidade Federal do Rio de Janeiro, Rio de Janeiro, Brazil, \\ ${ }^{2}$ Instituto Gonçalo Moniz, Fundação Oswaldo Cruz (Fiocruz), Salvador, Brazil, ${ }^{3}$ Instituto Oswaldo Cruz, Fiocruz, Rio de \\ Janeiro, Brazil, ${ }^{4}$ Instituto de Biofísica Carlos Chagas Filho, Universidade Federal do Rio de Janeiro, Rio de Janeiro, Brazil
}

\section{OPEN ACCESS}

Edited by:

Magdalena Plebanski,

Monash University, Australia

Reviewed by:

Mark von Itzstein,

Griffith University, Australia

Thomas Jacobs,

Bernhard-Nocht-Institut für

Tropenmedizin, Germany

${ }^{*}$ Correspondence:

Alexandre Morrot

morrot@micro.ufri.br;

Célio Geraldo Freire-de-Lima

celio@biof.ufrj.br

Specialty section:

This article was submitted to

Microbial Immunology,

a section of the journal

Frontiers in Microbiology

Received: 08 March 2017 Accepted: 29 May 2017

Published: 09 June 2017

Citation:

Gomes PS, Feijó DF, Morrot A and Freire-de-Lima CG (2017) Decoding

the Role of Glycans in Malaria.

Front. Microbiol. 8:1071.

doi: 10.3389/fmicb.2017.01071
Complications arising from malaria are a concern for public health authorities worldwide, since the annual caseload in humans usually exceeds millions. Of more than 160 species of Plasmodium, only 4 infect humans, with the most severe cases ascribed to Plasmodium falciparum and the most prevalent to Plasmodium vivax. Over the past 70 years, since World War II, when the first antimalarial drugs were widely used, many efforts have been made to combat this disease, including vectorial control, new drug discoveries and genetic and molecular approaches. Molecular approaches, such as glycobiology, may lead to new therapeutic targets (both in the host and the parasites), since all interactions are mediated by carbohydrates or glycan moieties decorating both cellular surfaces from parasite and host cells. In this review, we address the carbohydrate-mediated glycobiology that directly affects Plasmodium survival or host resistance.

Keywords: malaria, glycobiology, carbohydrate-targets, Plasmodium falciparum

\section{INTRODUCTION}

Malaria is caused by a protozoan of the Plasmodium genus, which belongs to the Apicomplexans phylum, an obligatory parasite (Kishore et al., 2013). Only in the last two decades has there been a significant reduction in malaria caseloads, and, according to the latest World Health Organization (WHO) records, cases have dropped significantly, i.e., from 262 million in 2000 to 214 million in 2015 (WHO, 2015). It is still a serious condition, however, noteworthy when compared to other pathologies of equal importance worldwide, due to its high prevalence (Binns and Low, 2015). Efforts toward the elimination of malaria involve the extermination of its vectors, and parasites and universal access to prevention (diagnosis and earlier treatment); this includes the discovery of new drugs, to deal with the high number of drug-resistant strains (Tanner and Hommel, 2010; Feng et al., 2016).

The first malaria drug treatments began with the use of quinine as the active ingredient (Parola and Miller, 2002). During World War II, a quinine-derivative, chloroquine, was widely used and treated as a "top secret" (Loff and Cordner, 1999; Skvara, 2004). Chloroquine was associated with many benefits (low cost, efficacy, and safety) (Kofoed et al., 2003; Savarino et al., 2006). Quininebased drugs were replaced by Artemisinin derivatives and other drugs; and the use of Artemisininbased Combined Therapies (ACT) is now recommended (Visser et al., 2014; Watsierah and Ouma, 2014; Pousibet-Puerto et al., 2016) to eliminate the blood phases, since in the exoerythrocytic phase (asymptomatic phase), there are no obvious symptoms for early treatment (Imrie et al., 2007).

Most of these drugs are still in use today in different doses, depending on the infective species and host background (Achan et al., 2011). Resistance is usually accompanied by a range of genetic 
diversity, and a high level of polymorphism, crucial to spreading these infective parasites but also after the widespread use of drugs, the first resistance-cases have appeared, and it seems that drugs have an "expiration date" this has also been observed in different malaria-infected patients in different regions, such as Thailand and Papua New Guinea (Cui et al., 2003; Brito and Ferreira, 2011). For example, Plasmodium falciparum shows high antigenic variation, with more than 60 coding variations of the $P$. falciparum erythrocyte membrane protein 1 (PfEMP-1), directly related to the virulence and lethality of the infection of this species (Arnot and Jensen, 2011). On the other hand, may present variations in the merozoite surface protein MSP-3 $\alpha$ is a multi-gene family important in P. falciparum and Plasmodium vivax, acting as "decoys" for antigenic diversity during RBCs invasion (Rice et al., 2014). CSP genes or circumsporozoite protein (CSP) in sporozoite surface, thrombospondin-related anonymous protein/sporozoite surface protein 2 (TRAP) or else in $P$. vivax apical membrane antigen 1 (AMA1) in ectodomain and C-terminal region of MSP-1 as a immunodominant antigen that was studied with recombinant protein (MSP119) as a novel potential vaccine (Rocha et al., 2017) and liver stage antigen (LSA1) also studied in malaria vaccine approaches (Pichyangkul et al., 2008).Thus, these and many more key proteins at each Plasmodium stage open up the "branches" for studies of this type of interactions, as seen in glycobiology.

\section{CARBOHYDRATES IN MALARIA: APPROACH FOR POTENTIAL DRUG TARGET DISCOVERY}

Glycosaminoglycans (GAGs) are abundant in both host and parasites; they are composed of basic units of carbohydrates that rearrange themselves in various ways, changing function and location (Griffin and Hsieh-Wilson, 2013). Glycobiological approaches investigate the influence of these carbohydrates on host-parasite binding interactions, such as glycolytic enzymes that are adequate in predicting a good understanding of parasite metabolism and glycosylation of malaria proteins. The first evidence about sugars mediatING the parasitered blood cell invasion was cited by Miller et al. (1977). Experiments determinated that O-linked oligosaccharides, such as NeuNAc and GalNac, were found in high concentration $(20 \mathrm{mM})$ and inhibited the parasite intracellular invasion in RBCs (Pasvol, 1984). Other sugars such as Gal ( $\beta 1$ 3) GalNAc disaccharide associated with glycophorin was more inhibitory in the same context (Hermentin et al., 1984).

Thus, these tools give support to studies currently in development in this regard. In addition, some pathogenassociated molecular patterns (PAMPs) consist primarily of carbohydrates structures, although these are not yet well known or understood in malaria parasites (Hoving et al., 2014). However, recently, the most discussed PAMPs are GPI anchores, haemozoin, and immunostimulatory nucleic acid motifs (Gazzinelli et al., 2014).
Other crucial receptor crucial, that requires specific receptorligand interactions to RBC invasion and cytoadherence in malaria, is Duffy-binding-like domains (DBLs). In P. vivax and $P$. knowlesi, parasites invade RBC exclusively through the DARC receptors (Duffy antigen receptor for chemokines). However, in P. knowlesi DBL domain (Pkalpa-DBL) to due a immune pressure they seems development a evasion strategy to run away, mapping to opposite surface of the DBL.

Spitzmuller and Mestres (2013) addressed the design of a generation of new antimalarials drugs. A major challenge is to identify $P$. falciparum proteins, among million possible combinations that can be targeted at the same time by the just one drug. In their studies, they analyzed databases and to identify drugs with multi protein targets, because the drugs until now supported specific protein targets, which in a few time allows the parasite to mutate only at this target reaching. Unlikely, Artemisinin which is regarded as a multitarget drug, maintaining as a new generation drug and which is advocated throughout malaria treatment (Spitzmuller and Mestres, 2013).

Still regarding innate immunity, there are two major families of pattern recognition receptors (PPR) predominantly expressed by cells of innate immune system are TLRs and C-type lectin receptors (CLRs). CLRs are important for the immune response against parasites, and in some studies example has been observed that, for example, CLRs are related with cerebral malaria in mice infected by Plasmodium berghei, and CARD9 is upregulated, but CARD9 ${ }^{-/-}$mice were not protected from infection, suggesting that the CARD9 receptor influences infectivity by the plasmodium but in its absence (as demonstrated in knockout animals) does not prevent the disease from occurring (McGuinness et al., 2003). Another study conducted with $P$. chabaudi demonstrated that the mannose receptor C type 2 (MRC2) increased with parasitemia, but tolllike receptors and sialoadhesin decreased in contrast to other MRCs (1 and 2), and that decreased with parasitemia in P. yoelii, suggesting the importance of lectin-receptors in the development of mounting of the immune response (Rosanas-Urgell et al., 2012).

Studies regarding parasite sugar supply demand has increased in the last decades, given that Plasmodium parasites require a high sugar demand to replicate. These parasites also show the ability to manipulate vector behavior to ensure survival, including increased sugar seeking, although it is unclear how this manipulation affects vector-plant interactions and sugar uptake (Nyasembe et al., 2014). Parasite manipulation in search of sugar supplies has been described as established at the moment of vector infection. Plasmodium present in the bloodstream require glucose, which crosses the plasma membranes and enters the parasite cytosol (Coppi et al., 2005; von Itzstein et al., 2008; Bertolino and Bowen, 2015; Swearingen et al., 2016). The parasites are able expose the RBC hexose transporter to facilitate sugar nucleotide uptake, allowing Plasmodium to biosynthesize certain glycans for maintenance (Cova et al., 2015). After the release of the sequence in the PlasmoDB, database facilitated the search for tools in interventions in this receptor for therapeutic 
purposes. The hexoses receptor (PfHT) has been widely studied, because its decrease implies in the lower supply of glucose to parasites and causing the plasmodium elimination (Bahl et al., 2003).

The surface of infected red blood cells (RBCs) are rich in glycophorins and Plasmodium possesses some proteins like erythrocytes binding-like (EBL) and reticulocyte binding-like (Rh) protein families that recognize them, playing a critical role in attachment in invasion (Davidson and Gowda, 2001; Salinas et al., 2014), Studies demonstrated that glycophorins as play crucial role in Plasmodium invasion, in absence of glycophorins A relatively resistant to the invasion in red blood cells (Pasvol, 1984). Other portion of glycophorin A has sialic acid residues, which is known as EBA-175 (175 kDa), and it mediates binding of $P$. falciparum to RBCs. A part of this, EBA-175 is highly conserved and rich in cysteine, is referred to as F2 (PfF2) and it has receptor binding sites that have been studied as a possible recombinant protein in malaria vaccines trials (Pattnaik et al., 2007).

In Tham et al. (2015) the cytoplasmatic tails of these proteins were phosphorylated in vitro and blocked RBC invasion, evidencing the importance of these proteins for invasion (Tham et al., 2015).

In addition to studies on the interactions between the parasite and carbohydrates in RBCs, it has been demonstrated that blood type (ABO, Lewis, Duffy, and others surface antigens) influences erythrocyte parasitism, with certain types more susceptible to Plasmodium infection (Cooling, 2015). Studies indicate that individuals of blood group A are highly susceptible to $P$. falciparum induced-malaria, while blood group $O$ has been shown to be protective against complicated cases (Fischer and Boone, 1998; Lell et al., 1999). The CSP and TRAP domains on the sporozoite that mediate the adhesive contact with the sulphated glycoconjugates on the surface of hepatocytes allow plasmodium invasion to the bloodstream. Thus, these proteins are extremely important for the parasite, since it is from the entry in the hepatocytes that the cycle begins. Taking this into account, these same proteins have been studied extensively, including in the manufacturing of antimalarial vaccines, such as RTS,S (Coppi et al., 2005; Swearingen et al., 2016). Despite having obtained good results in treating mice with anti-CSP, it has been verified that, in the absence of this protein, the cycle of hepatocyte invasion continues normally, since after invasion CSPs are less expressed, while other proteins become highly expressed (Bertolino and Bowen, 2015).

As the Plasmodium parasite uses sugar-requirements to ensure survival, approaches with drug-targeting carbohydrates have increasingly been proposed as possible treatments. Regarding in vitro studies, Plaimas et al. (2013) investigated a database of genetic information from Plasmodium to try to decipher which points of the proteins expressed could be future of therapeutic targets. 22 potential targets, refined the search by removing false positives, leaving only 5 targets, among them, glutamyl-tRNA (gln) aminotransferase and with a known inhibitor of this transferase 6-diazo-5-oxonorleucine (Don). The tests were carried out and the growth of the parasite decreased both in vitro and in vivo in Swiss mice, despite the side effects related to the dosage (Plaimas et al., 2013). Similar results have recently been observed with $\mathrm{DON}$ in experimental cerebral malaria mice models, although this compound has shown inhibitory effects by blocking CD8+ T-cell effector function, which is the highest cause of mice death (Gordon et al., 2015). On the other hand, other studies indicate that mice mortality was attenuated due to GPI anchors, not $\mathrm{T}$ cells, since several literature reports indicate the importance of glycophosphatidylinositol (GPI) anchors for the success of Plasmodium infection (Naik et al., 2000). CSP have also been associated to GPI, which have a canonical domain in the $\mathrm{COOH}$ portion, although this has not yet been demonstrated (Coppi et al., 2005).

Of significance, people living in endemic areas are more resistant to malaria, due to the production of antibodies against GPI anchors (Vijaykumar et al., 2001).

In addition to inhibitors that hinder this type of parasitehost interaction, mice immunized with the glycan moiety of GPIs were able to produce anti-GPI antibodies to prevent progression to cerebral malaria (Schofield et al., 2002). It has been reported that a microbial polyssacharide, Gellan Gum (GG), containing a sugar moiety produced by the Sphingomonas (Pseudomonas) elodea bacterium, strongly inhibited parasite invasion; this also inhibits growth (strains 3D7 and Dd2), demonstrating that "natural" sugars can also contain Plasmodium effects (Recuenco et al., 2014). In human malaria, successive pregnancies contribute to resistance against Plasmodium, which mediates binding to chondroitin sulfate A (CSA) in the placenta through the VAR2CSA protein (Salanti et al., 2004; Gamain et al., 2005); this leads to accumulation of Plasmodium parasites in the placenta, resulting in severe clinical consequences for both mother and child (Resende et al., 2008), such that the investigation of this interaction is a viable target for vaccines (Clausen et al., 2012; Fried and Duffy, 2017). Through all this information about the various receivers composed by sugar and the interactions required these reinforce the importance of deciphering the nature of glycan functions in malaria in order to improve approaches for predicting drug-target interactions for this complex.

\section{AUTHOR CONTRIBUTIONS}

PSG, DFF, AM, and CGF-de-L wrote the paper. All authors read and approved the final version of the manuscript.

\section{ACKNOWLEDGMENTS}

This work was supported by grants from the Conselho Nacional de Desenvolvimento Científico e Tecnológico do Brasil (CNPq) and the Fundação de Amparo à Pesquisa do Estado do Rio de Janeiro (FAPERJ). 


\section{REFERENCES}

Achan, J., Talisuna, A. O., Erhart, A., Yeka, A., Tibenderana, J. K., Baliraine, F. N., et al. (2011). Quinine, an old anti-malarial drug in a modern world: role in the treatment of malaria. Malar. J. 10:144. doi: 10.1186/1475-287510-144

Arnot, D. E., and Jensen, A. T. (2011). Antigenic variation and the genetics and epigenetics of the PfEMP1 erythrocyte surface antigens in Plasmodium falciparum Malaria. Adv. Appl. Microbiol. 74, 77-96. doi: 10.1016/B978-0-12-387022-3.00007-0

Bahl, A., Brunk, B., Crabtree, J., Fraunholz, M. J., Gajria, B., Grant, G. R., et al. (2003). PlasmoDB: the Plasmodium genome resource. A database integrating experimental and computational data. Nucleic Acids Res. 31, 212-215. doi: 10.1093/nar/gkg081

Bertolino, P., and Bowen, D. G. (2015). Malaria and the liver: immunological hide-and-seek or subversion of immunity from within? Front. Microbiol. 6:41. doi: 10.3389/fmicb.2015.00041

Binns, C., and Low, W. Y. (2015). Malaria continues as a major public health problem. Asia Pac. J. Public Health 27, 261-262. doi: $10.1177 / 1010539515583388$

Brito, C. F., and Ferreira, M. U. (2011). Molecular markers and genetic diversity of Plasmodium vivax. Mem. Inst. Oswaldo Cruz 106 (Suppl. 1), 12-26. doi: 10.1590/S0074-02762011000900003

Clausen, T. M., Christoffersen, S., Dahlback, M., Langkilde, A. E., Jensen, K. E., Resende, M., et al. (2012). Structural and functional insight into how the Plasmodium falciparum VAR2CSA protein mediates binding to chondroitin sulfate A in placental malaria. J. Biol. Chem. 287, 23332-23345. doi: 10.1074/jbc.M112.348839

Cooling, L. (2015). Blood Groups in Infection and Host Susceptibility. Clin. Microbiol. Rev. 28, 801-870. doi: 10.1128/CMR.00109-14

Coppi, A., Pinzon-Ortiz, C., Hutter, C., and Sinnis, P. (2005). The Plasmodium circumsporozoite protein is proteolytically processed during cell invasion. J. Exp. Med. 201, 27-33. doi: 10.1084/jem.20040989

Cova, M., Rodrigues, J. A., Smith, T. K., and Izquierdo, L. (2015). Sugar activation and glycosylation in Plasmodium. Malar. J. 14, 427. doi: 10.1186/s12936-015-0949-Z

Cui, L., Mascorro, C. N., Fan, Q., Rzomp, K. A., Khuntirat, B., Zhou, G., et al. (2003). Genetic diversity and multiple infections of Plasmodium vivax malaria in Western Thailand. Am. J. Trop. Med. Hyg. 68, 613-619. doi: 10.4269/ajtmh.2003.68.613

Davidson, E. A., and Gowda, D. C. (2001). Glycobiology of Plasmodium falciparum. Biochimie 83, 601-604. doi: 10.1016/S0300-9084(01)01316-5

Feng, J., Liu, J., Feng, X., Zhang, L., Xiao, H., and Xia, Z. (2016). Towards Malaria Elimination: Monitoring and Evaluation of the "1-3-7" Approach at the China-Myanmar Border. Am. J. Trop. Med. Hyg. 95, 806-810. doi: 10.4269/ajtmh.15-0888

Fischer, P. R., and Boone, P. (1998). Short report: severe malaria associated with blood group. Am. J. Trop. Med. Hyg. 58, 122-123.

Fried, M., and Duffy, P. E. (2017). Malaria during pregnancy. Cold Spring Harb. Perspect. Med. 7:a025551. doi: 10.1101/cshperspect. a025551

Gamain, B., Trimnell, A. R., Scheidig, C., Scherf, A., Miller, L. H., and Smith, J. D. (2005). Identification of multiple chondroitin sulfate A (CSA)-binding domains in the var2CSA gene transcribed in CSA-binding parasites. J. Infect. Dis. 191, 1010-1013. doi: 10.1086/428137

Gazzinelli, R. T., Kalantari, P., Fitzgerald, K. A., and Golenbock, D. T. (2014). Innate sensing of malaria parasites. Nat. Rev. Immunol. 14, 744-757. doi: $10.1038 /$ nri3742

Gordon, E. B., Hart, G. T., Tran, T. M., Waisberg, M., Akkaya, M., Kim, A. S., et al. (2015). Targeting glutamine metabolism rescues mice from late-stage cerebral malaria. Proc. Natl. Acad. Sci. U.S.A. 112, 13075-13080. doi: $10.1073 /$ pnas. 1516544112

Griffin, M. E., and Hsieh-Wilson, L. C. (2013). Synthetic probes of glycosaminoglycan function. Curr. Opin. Chem. Biol. 17, 1014-1022. doi: 10.1016/j.cbpa.2013.09.015

Hermentin, P., Paulsen, H., Kolar, C., and Enders, B. (1984). Plasmodium falciparum: carbohydrates as receptor sites of invasion. Exp. Parasitol. 58, 290-306.
Hoving, J. C., Wilson, G. J., and Brown, G. D. (2014). Signalling C-type lectin receptors, microbial recognition and immunity. Cell. Microbiol. 16, 185-194. doi: 10.1111/cmi.12249

Imrie, H., Fowkes, F. J., Michon, P., Tavul, L., Reeder, J. C., and Day, K. P. (2007) Low prevalence of an acute phase response in asymptomatic children from a malaria-endemic area of Papua New Guinea. Am. J. Trop. Med. Hyg. 76, 280-284. doi: 10.4269/ajtmh.2007.76.280

Kishore, S. P., Stiller, J. W., and Deitsch, K. W. (2013). Horizontal gene transfer of epigenetic machinery and evolution of parasitism in the malaria parasite Plasmodium falciparum and other apicomplexans. BMC Evol. Biol. 13:37. doi: 10.1186/1471-2148-13-37

Kofoed, P. E., Poulsen, A., Co, F., Hedegaard, K., Aaby, P., and Rombo, L. (2003). No benefits from combining chloroquine with artesunate for three days for treatment of Plasmodium falciparum in Guinea-Bissau. Trans. R. Soc. Trop. Med. Hyg. 97, 429-433. doi: 10.1016/S0035-9203(03)90078-2

Lell, B., May, J., Schmidt-Ott, R. J., Lehman, L. G., Luckner, D., Greve, B., et al. (1999). The role of red blood cell polymorphisms in resistance and susceptibility to malaria. Clin. Infect. Dis. 28, 794-799. doi: 10.1086/515193

Loff, B., and Cordner, S. (1999). World War II malaria trials revisited. Lancet 353, 1597.

McGuinness, D. H., Dehal, P. K., and Pleass, R. J. (2003). Pattern recognition molecules and innate immunity to parasites. Trends Parasitol. 19, 312-319. doi: 10.1016/S1471-4922(03)00123-5

Miller, L. H., Haynes, J. D., McAuliffe, F. M., Shiroishi, T., Durocher, J. R., and McGinniss, M. H. (1977). Evidence for differences in erythrocyte surface receptors for the malarial parasites, Plasmodium falciparum and Plasmodium knowlesi. J. Exp. Med. 146, 277-281.

Naik, R. S., Davidson, E. A., and Gowda, D. C. (2000). Developmental stage-specific biosynthesis of glycosylphosphatidylinositol anchors in intraerythrocytic Plasmodium falciparum and its inhibition in a novel manner by mannosamine. J. Biol. Chem. 275, 24506-24511. doi: 10.1074/jbc.M002151200

Nyasembe, V. O., Teal, P. E., Sawa, P., Tumlinson, J. H., Borgemeister, C., and Torto, B. (2014). Plasmodium falciparum infection increases Anopheles gambiae attraction to nectar sources and sugar uptake. Curr. Biol. 24, 217-221. doi: 10.1016/j.cub.2013.12.022

Parola, P., and Miller, R. S. (2002). Quinine in the modern treatment of falciparum malaria. Lancet Infect. Dis. 2, 206-207. doi: 10.1016/S1473-3099(02)00237-2

Pasvol, G. (1984). Receptors on red cells for Plasmodium falciparum and their interaction with merozoites. Philos. Trans. R. Soc. Lond. B. Biol. Sci. 307, 189-200.

Pattnaik, P., Shakri, A. R., Singh, S., Goel, S., Mukherjee, P., and Chitnis, C. E. (2007). Immunogenicity of a recombinant malaria vaccine based on receptor binding domain of Plasmodium falciparum EBA-175. Vaccine 25, 806-813. doi: 10.1016/j.vaccine.2006.09.048

Pichyangkul, S., Kum-Arb, U., Yongvanitchit, K., Limsalakpetch, A., Gettayacamin, M., Lanar, D. E., et al. (2008). Preclinical evaluation of the safety and immunogenicity of a vaccine consisting of Plasmodium falciparum liver-stage antigen 1 with adjuvant AS01B administered alone or concurrently with the RTS,S/AS01B vaccine in rhesus primates. Infect. Immun. 76, 229-238. doi: 10.1128/IAI.00977-07

Plaimas, K., Wang, Y., Rotimi, S. O., Olasehinde, G., Fatumo, S., Lanzer, M., et al. (2013). Computational and experimental analysis identified 6-diazo5-oxonorleucine as a potential agent for treating infection by Plasmodium falciparum. Infect. Genet. Evol. 20, 389-395. doi: 10.1016/j.meegid.2013.09.019

Pousibet-Puerto, J., Salas-Coronas, J., Sanchez-Crespo, A., Molina-Arrebola, M. A., Soriano-Perez, M. J., Gimenez-Lopez, M. J., et al. (2016). Impact of using artemisinin-based combination therapy (ACT) in the treatment of uncomplicated malaria from Plasmodium falciparum in a non-endemic zone. Malar. J. 15, 339. doi: 10.1186/s12936-016-1408-1

Recuenco, F. C., Kobayashi, K., Ishiwa, A., Enomoto-Rogers, Y., Fundador, N. G., Sugi, T., et al. (2014). Gellan sulfate inhibits Plasmodium falciparum growth and invasion of red blood cells in vitro. Sci. Rep. 4:4723. doi: 10.1038/srep04723

Resende, M., Nielsen, M. A., Dahlback, M., Ditlev, S. B., Andersen, P., Sander, A. F., et al. (2008). Identification of glycosaminoglycan binding regions in the Plasmodium falciparum encoded placental sequestration ligand, VAR2CSA. Malar. J. 7:104. doi: 10.1186/1475-2875-7-104

Rice, B. L., Acosta, M. M., Pacheco, M. A., Carlton, J. M., Barnwell, J. W., and Escalante, A. A. (2014). The origin and diversification of the merozoite surface 
protein 3 (msp3) multi-gene family in Plasmodium vivax and related parasites. Mol. Phylogenet. Evol. 78, 172-184. doi: 10.1016/j.ympev.2014.05.013

Rocha, M. V., Francoso, K. S., Lima, L. C., Camargo, T. M., Machado, R. L., Costa, F. T., et al. (2017). Generation, characterization and immunogenicity of a novel chimeric recombinant protein based on Plasmodium vivax AMA-1 and MSP119. Vaccine 35, 2463-2472. doi: 10.1016/j.vaccine.2017. 03.023

Rosanas-Urgell, A., Martin-Jaular, L., Ricarte-Filho, J., Ferrer, M., Kalko, S., Kimura, E., et al. (2012). Expression of non-TLR pattern recognition receptors in the spleen of BALB/c mice infected with Plasmodium yoelii and Plasmodium chabaudi chabaudi AS. Mem. Inst. Oswaldo Cruz 107, 410-415. doi: $10.1590 /$ S0074-02762012000300017

Salanti, A., Dahlback, M., Turner, L., Nielsen, M. A., Barfod, L., Magistrado, P., et al. (2004). Evidence for the involvement of VAR2CSA in pregnancy-associated malaria. J. Exp. Med. 200, 1197-1203. doi: 10.1084/jem.200break41579

Salinas, N. D., Paing, M. M., and Tolia, N. H. (2014). Critical glycosylated residues in exon three of erythrocyte glycophorin A engage Plasmodium falciparum EBA-175 and define receptor specificity. MBio 5, e01606-e01614. doi: 10.1128/mBio.01606-14

Savarino, A., Lucia, M. B., Giordano, F., and Cauda, R. (2006). Risks and benefits of chloroquine use in anticancer strategies. Lancet Oncol. 7, 792-793. doi: 10.1016/S1470-204570875-0

Schofield, L., Hewitt, M. C., Evans, K., Siomos, M. A., and Seeberger, P. H. (2002). Synthetic GPI as a candidate anti-toxic vaccine in a model of malaria. Nature 418, 785-789. doi: 10.1038/nature00937

Skvara, F. C. (2004). World War II: exhibit pages (The Red Cross society, blood transfusions, discovery of penicillin, malaria). Scalpel Tongs 48, 60-64.

Spitzmuller, A., and Mestres, J. (2013). Prediction of the P. falciparum target space relevant to malaria drug discovery. PLoS Comput. Biol. 9:e1003257. doi: 10.1371/journal.pcbi.1003257

Swearingen, K. E., Lindner, S. E., Shi, L., Shears, M. J., Harupa, A., Hopp, C. S., et al. (2016). Interrogating the Plasmodium Sporozoite Surface: Identification of Surface-Exposed Proteins and Demonstration of Glycosylation on CSP and TRAP by Mass Spectrometry-Based Proteomics. PLoS Pathog. 12:e10 05606. doi: 10.1371/journal.ppat.1005606

Tanner, M., and Hommel, M. (2010). Towards malaria elimination-a new thematic series. Malar. J. 9:24. doi: 10.1186/1475-2875-9-24

Tham, W. H., Lim, N. T., Weiss, G. E., Lopaticki, S., Ansell, B. R., Bird, M., et al. (2015). Plasmodium falciparum adhesins play an essential role in signalling and activation of invasion into human erythrocytes. PLoS Pathog. 11:e1005343. doi: 10.1371/journal.ppat.1005343

Vijaykumar, M., Naik, R. S., and Gowda, D. C. (2001). Plasmodium falciparum glycosylphosphatidylinositol-induced TNF- $\alpha$ secretion by macrophages is mediated without membrane insertion or endocytosis. J. Biol. Chem. 276, 6909-6912. doi: 10.1074/jbc.C100007200

Visser, B. J., Wieten, R. W., Kroon, D., Nagel, I. M., Belard, S., van Vugt, M., et al. (2014). Efficacy and safety of artemisinin combination therapy (ACT) for non-falciparum malaria: a systematic review. Malar. J. 13:463. doi: 10.1186/1475-2875-13-463

von Itzstein, M., Plebanski, M., Cooke, B. M., and Coppel, R. L. (2008). Hot, sweet and sticky: the glycobiology of Plasmodium falciparum. Trends Parasitol. 24, 210-218. doi: 10.1016/j.pt.2008.02.007

Watsierah, C. A., and Ouma, C. (2014). Access to artemisinin-based combination therapy (ACT) and quinine in malaria holoendemic regions of western Kenya. Malar. J. 13:290. doi: 10.1186/1475-2875-13-290 WHO (2015). World Malaria Report 2015. Geneva: WHO.

Conflict of Interest Statement: The authors declare that the research was conducted in the absence of any commercial or financial relationships that could be construed as a potential conflict of interest.

Copyright $\odot 2017$ Gomes, Feijó, Morrot and Freire-de-Lima. This is an open-access article distributed under the terms of the Creative Commons Attribution License (CC $B Y)$. The use, distribution or reproduction in other forums is permitted, provided the original author(s) or licensor are credited and that the original publication in this journal is cited, in accordance with accepted academic practice. No use, distribution or reproduction is permitted which does not comply with these terms. 